\title{
1 The effect of dynamic topography and gravity on lithospheric effective elastic thickness estimation: a case study
}

3 Yongliang Bai ${ }^{\mathrm{a}, \mathrm{b}, *}$, Dongdong Dong ${ }^{\mathrm{b}}$, Jon F. Kirby ${ }^{\mathrm{c}}$, Simon E. Williams ${ }^{\mathrm{d}}$, Zhenjie Wang ${ }^{\mathrm{a}}$ 4

5 a School of Geosciences, China University of Petroleum, Qingdao 266580, China

$6{ }^{\mathrm{b}}$ Key Laboratory of Marine Geology and Environment, Institute of Oceanology, Chinese Academy

7 of Sciences, Qingdao 266071, China

$8{ }^{\mathrm{c}}$ School of Earth and Planetary Sciences, Curtin University, WA 6845, Australia

$9{ }^{\mathrm{d}}$ EarthByte Group, School of Geosciences, University of Sydney, NSW 2006, Australia 10

12 Abbreviated title: Improving $T_{e}$ estimations by dynamic modelling

*Corresponding author, E-mail address: yongliang.bai1986@gmail.com (Y.Bai). 


\section{SUMMARY}

Lithospheric effective elastic thickness $\left(T_{e}\right)$, a proxy for plate strength, is helpful for the understanding of subduction characteristics. Affected by curvature, faulting and magma activity, lithospheric strength near trenches should be weakened but some regional inversion studies have shown much higher $T_{e}$ values along some trenches than in their surroundings. In order to improve $T_{e}$ estimation accuracy, here we discuss the long-wavelength effect of dynamic topography and gravity on $T_{e}$ estimation by taking the Izu-Bonin-Mariana (IBM) Trench as a case study area. We estimate the long-wavelength influence of the density and negative buoyancy of the subducting slab on observed gravity anomalies and seafloor topography. The residual topography and gravity are used to map $T_{e}$ using the fan-wavelet coherence method. Maps of $T_{e}$, both with and without the effects of dynamic topography and slab gravity anomaly, contain a band of high- $T_{e}$ values along the IBM Trench, though these values and their errors are lower when slab effects are accounted for. Nevertheless, tests show that the $T_{e}$ map is relatively insensitive to the choice of slab-density modelling method, even though the dynamic topography and slab-induced gravity anomaly vary considerably when the slab density is modelled by different methods. The continued presence of a high- $T_{e}$ band along the trench after application of dynamic corrections shows that, before using 2D inversion methods to estimate Te variations in subduction zones, there are other factors that should be considered besides the slab dynamic effects on the overriding plate. 
36 Key words: effective elastic thickness; lithospheric strength; Izu-Bonin-Mariana 37 subduction system; slab density; dynamic topography; slab gravity anomaly 


\section{INTRODUCTION}

The physical properties of the lithosphere govern intra-plate convergence and inner-plate deformation and therefore exert a strong control on trench shape and

41 back-arc spreading (Forsyth and Uyeda, 1975; Niu, 2014). One of the most important 42 of these physical properties is the flexural rigidity, which is a measure of the 43 lithosphere's resistance to bending under applied loads, whether from above, below or within (Burov and Diament, 1995; Watts et al., 1980). The effective elastic thickness $\left(T_{e}\right)$, a quantity which can be estimated from the coherence between topography and Bouguer gravity anomaly, is related to lithospheric flexural rigidity (McKenzie and 47 Fairhead, 1997) and its rheological structure (Oruç and Sönmez, 2017). Available gravity and topography/bathymetry data can be used to compute lateral variations of $T_{e}$, and therefore study the geodynamic characteristics of a region, including subduction zones. For example, Pérez-Gussinyé et al. (2008) estimated the geodynamic relationship between subduction geometry and lithospheric strength along coherence technique, while Ratheesh Kumar et al. (2013) evaluated the convergence

Watts, 2009) because thermal softening induced by magmatic activity reduces

lithospheric strength (Ebinger et al., 1989). The existence of present-day back-arc spreading, and active magmatic arcs and forearcs across the Izu-Bonin-Mariana (IBM, 
Figure 1) arc region (Stern et al., 2004) demonstrates that there exists considerable magmatic activity. Hence, the lithosphere of the IBM regions surrounded by arcs should be weak. The downward bending of the incoming plate by subduction introduces significant fracturing and so reduces the strength of the incoming plate near trench (Bry and White, 2007; McNutt and Menard, 1982). Therefore, the lithosphere at the trench and neighboring regions should have a reduced $T_{e}$ value. Indeed, studies using forward and inverse modelling of one-dimensional (1D) gravity/bathymetry profiles along the IBM subduction zone found reduced $T_{e}$ values (Billen and Gurnis, 2005; Bry and White, 2007; Contreras-Reyes and Osses, 2010; Hunter and Watts, 2016; Zhang et al., 2014). However, 2D $T_{e}$-estimation methods have shown a band along the IBM Trench with obviously higher $T_{e}$ values than the surroundings ( $\underline{\text { Chen et }}$ al., 2013; Kalnins and Watts, 2009).

Along the Andean margin, the effects of slab gravity and dynamic topography on estimated $T_{e}$ values are negligible (Pérez-Gussinyé et al., 2008). The subducting Nazca plate (younger than 50 m.y.) has a relatively small slab density contrast with the mantle and a small sinking force, resulting in a small slab gravity anomaly and dynamic topography. However, the IBM trench sees the subduction of the oldest oceanic plate (older than 130 m.y.) on the Earth and is under strong back-arc spreading (Stern et al., 2004). Therefore, the effects of dynamic topography and slab gravity along the IBM Trench are, in contrast, non-negligible for $T_{e}$ studies. Here we estimate these effects on $T_{e}$ estimations based on different slab density modelling methods. 


\section{METHODOLOGY}

The effective elastic thickness $\left(T_{e}\right)$ is related to the lithosphere's flexural rigidity $85(D)$ by:

$$
D=\frac{E T_{e}^{3}}{12\left(1-v^{2}\right)},
$$

87 where $E$ is Young's modulus, $v$ is Poisson's ratio, and both $E$ and $v$ can be treated as constants (Walcott, 1970). Under long-wavelength loading, the lithosphere is 89 isostatically compensated by a mechanism such as Airy isostasy, and the coherence 90 between topography and Bouguer anomaly tends to a value of 1 (Chen et al., 2015; 91 Pérez-Gussinyé et al., 2004). Short-wavelength loads that can be supported by 92 lithospheric strength result in almost no lithospheric flexure, in which case the 93 coherence between loading and Bouguer anomaly tends to zero (Forsyth, 1985; 94 Pérez-Gussinyé et al., 2004). Simons and Olhede (2013) give an expression for the coherence transition wavelength, being the wavelength separating compensated from supported loads, and at which the coherence has a value of 0.5 . A related expression is

97 provided by the flexural wavelength $(\lambda)$, being the wavelength of the depression due 98 to a point surface load, and related to $T_{e}$ (Macario et al., 1995):

$$
\lambda=2 \pi\left(\frac{E T_{e}^{3}}{12\left(1-v^{2}\right)} / \Delta \rho \mathrm{g}\right)^{1 / 4},
$$

100 where $\Delta \rho$ is the density contrast across the compensation surface (usually taken to 101 be the Moho), and $g$ is the acceleration due to gravity. Although the coherence 102 transition and flexural wavelengths are of the same order of magnitude, they do differ 
for very high or very low values of the initial subsurface-to-surface loading ratio 104 (Kirby and Swain, 2008).

\section{1 $T_{e}$ estimation using fan wavelet}

There are two main widely-used methods for mapping spatial variations in $T_{e}$ 108 based on the coherence between the Bouguer gravity anomaly and $\underline{2000}$ ) and the fan wavelet coherence method (Kirby, 2005; Kirby and Swain, 2004).

The multitaper method uses a moving window of fixed dimensions to obtain spatially varying coherence values across an area and from this constructs a $T_{e}$ map. The need to select a window size limits the multitaper method in two ways: firstly, flexure cannot be resolved when the window size is smaller than the flexural wavelength; secondly, a large window size cannot image detailed spatial variations in $T_{e}$ (Chen et al., 2013; Kalnins and Watts, 2009; Pérez-Gussinyé et al., 2008; Pérez-Gussinyé et al.,

117 2004). The fan wavelet method avoids these shortcomings, so we choose this method to estimate $T_{e}$ distribution in our research area. Nevertheless the fan wavelet method 119 faces the problem that the resolution of the $T_{e}$ map depends on the central 120 wavenumber $(\mathrm{CW})$ of the Morlet wavelet used in the wavelet analysis (Chen et al., $121 \quad$ 2015; Kirby, 2014).

Kirby and Swain (2004) constructed the fan wavelet by superposition of a series 123 of rotated Morlet wavelets, giving isotropic and complex wavelet coefficients. The 124 Fourier transform of the two dimensional (2D) Morlet wavelet is 
126 where $\left|\mathbf{k}_{0}\right|$ is the central wavenumber (CW), $u$ and $v$ are the components of the 2D 127 wavenumber vector $\mathbf{k}, s$ is the scale of the wavelet, and $\theta$ is its azimuth. Each Morlet 128 wavelet scale is related to an equivalent Fourier wavenumber, $k_{F}$, by $k_{F}=\left|\mathbf{k}_{0}\right| / s$ 129 (Kirby, 2005).

The wavelet transform is a space-domain convolution between the signal to be analyzed and the wavelet. This convolution is performed at all the selected scales and azimuths, and as such, reveals the harmonic content of the signal at each space-domain grid node and azimuth. The wavelet transform is most efficiently performed in the wavenumber domain where convolution becomes multiplication, yielding wavelet coefficients $B_{s \mathbf{x} \theta}$ via the equation:

$$
B_{s x \theta} \equiv B(s, \mathbf{x}, \theta)=\mathbf{F}^{-1}\left[\hat{b}(\mathbf{k}) \hat{\psi}_{s \theta}(\mathbf{k})\right],
$$

where $\mathbf{F}^{-1}$ is the inverse 2D Fourier transform operator, and $\hat{b}(\mathbf{k})$ is the Fourier transform of the space domain signal $b(\mathbf{x})$.

The 2D observed wavelet coherence $\left(\gamma_{\text {obs }}^{2}(s, \mathbf{x})\right)$ between observed Bouguer gravity anomaly and topography at scale $(s)$ and location $(\mathbf{x})$ is calculated by summing the wavelet cross- and co-spectra over azimuth (Kirby and Swain, 2008; Kirby and Swain,

$$
\gamma_{o b s}^{2}(s, \mathbf{x})=\frac{\left|\left\langle B_{s \mathbf{x} \theta} H_{s \mathbf{x} \theta}^{*}\right\rangle_{\theta}\right|^{2}}{\left\langle B_{s \mathbf{x} \theta} B_{s \mathbf{x} \theta}^{*}\right\rangle_{\theta}\left\langle H_{s \mathbf{x} \theta} H_{s \mathbf{x} \theta}^{*}\right\rangle_{\theta}},
$$

144 where $B_{s x \theta}$ and $H_{s x \theta}$ are the complex wavelet coefficients of Bouguer anomaly and 145 topography, respectively, the * indicates the complex conjugate, and \langle\rangle$_{\theta}$ represents 
averaging over Morlet wavelet azimuth.

The observed coherence is then inverted against the predictions of a thin, elastic plate model of plate flexure using the wavelet adaptation of the method of Forsyth (1985) by Swain and Kirby (2006). The inversion for $T_{e}$ is performed by comparing the observed coherence with the predicted coherence at each space-domain grid node, where the predicted coherence can be computed by (Chen et al., 2015; Kirby and

$\underline{\text { Swain, 2011) }}$

$$
\gamma_{p r e}^{2}(s, \mathbf{x})=\frac{\left(\mu_{T} \kappa_{T}+\mu_{B} \kappa_{B} f^{2} r^{2}\right)^{2}}{\left(\mu_{T}^{2}+\mu_{B}^{2} f^{2} r^{2}\right)\left(\kappa_{T}^{2}+\kappa_{B}^{2} f^{2} r^{2}\right)} .
$$

Here, $f$ is the subsurface to surface loading ratio which can be determined by:

$$
f^{2}(s, \mathbf{x})=\frac{\left\langle\left|W_{i}\right|^{2}\right\rangle_{\theta}}{r^{2}\left\langle\left|H_{i}\right|^{2}\right\rangle_{\theta}},
$$

where $W_{i}$ and $H_{i}$ are the wavelet coefficients of initial surface and subsurface loads which are assumed to be statistically independent (have random phase) (Forsyth, 1985) and are products of the inversion (Forsyth, 1985; Swain and Kirby, 2006). Other variables used in equation (6) are calculated from:

$$
\left\{\begin{array}{l}
\kappa_{B}=\Delta \rho_{2} / \varphi \\
\kappa_{T}=1-\Delta \rho_{1} / \varphi \\
\mu_{B}=2 \pi G \Delta \rho_{2}\left(1-\Delta \rho_{2} / \varphi\right) e^{-k Z_{m}} \\
\mu_{T}=2 \pi G \Delta \rho_{2}\left(-\Delta \rho_{1} / \varphi\right) e^{-k Z_{m}} \\
\varphi=D k^{4} / g+\left(\rho_{m}-\rho_{w}\right)
\end{array}\right.
$$

161 where $\Delta \rho_{1}=\rho_{b}-\rho_{*}, \Delta \rho_{2}=\rho_{m}-\rho_{b} ; r=\Delta \rho_{1} / \Delta \rho_{2} ; \rho_{*}$ is seawater or air density 162 depending on the setting (continent or ocean); $\rho_{m}, \rho_{b}$ and $\rho_{w}$ are densities of mantle, 163 basement and seawater respectively; $Z_{m}$ is the depth to the compensating interface (the 164 Moho); $g$ is the gravitational acceleration, $G$ is the Newtonian gravitational 
constant; and $k \equiv|\mathbf{k}|$ is the 1D wavenumber which can be replaced by the equivalent Fourier wavenumber in the fan wavelet case (Kirby, 2005).

The $T_{e}$ value at each grid node is obtained by minimizing the misfit between predicted and observed coherence (Chen et al., 2015; Kirby and Swain, 2011). Since the final $T_{e}$ resolution would be affected by central wavenumber values, we compute $T_{e}$ maps based on four different $\left|\mathbf{k}_{0}\right|$ values $(2.668,3.081,3.773$ and 5.336) as done

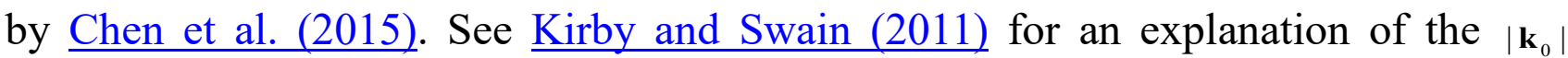
values. The values of the constants used for estimating $T_{e}$ are shown in Table 1 .

Error estimates on the coherence were obtained using the jackknife method of error estimation (Thomson and Chave, 1991) applied to wavelets (Kirby and Swain, 2013). The coherence errors were then used as weights on the difference between observed and predicted coherence in minimization of the square of the $\mathrm{L}_{2}$-norm (chi-squared statistic) (Kirby, 2014). Errors on $T_{e}$ were obtained from the width of the misfit curve in the parameter space (where $T_{e}$ is the only parameter) corresponding to a confidence level of 95\% (Press et al., 1992).

Kirby and Swain $(2008,2011)$ have performed extensive tests on the accuracy of the method under different scenarios using synthetic, fractal loading models. Results have been encouraging. Of particular note here is the test on a plate with a $T_{e}$ discontinuity, representing a fault or subduction zone (Kirby and Swain, 2008).

\subsection{Dynamic topography and slab gravity anomaly}

Loading of lithosphere is a key parameter for $T_{e}$ evaluations and loading is not 
limited to topographic variations. Figure 2 illustrates factors which include surface 188 loading such as mountains and seawater, and internal loading such as high-density 189 magmatic intrusions into the basement and dynamic forces from beneath the 190 lithosphere (Bry and White, 2007), referred to as under-loading in this paper. Here we convert the bathymetry to a rock-equivalent topography:

$$
h_{e q}(\mathbf{x})=\frac{\rho_{c}-\rho_{w}}{\rho_{c}} d(\mathbf{x}), \quad \forall d(\mathbf{x})<0
$$

where $d(\mathbf{x})$ is the bathymetry or topography at location $\mathbf{x}$ and $h_{e q}(\mathbf{x})$ is the equivalent topography at the same position. A similar conversion also should be used to calculate the equivalent topography of sediment cover when it is thick (Shi et al., 2017):

$$
h_{e q}(\mathbf{x})=\frac{\rho_{c}-\rho_{\mathrm{s}}}{\rho_{c}} d(\mathbf{x}), \forall d(\mathbf{x})<0 .
$$

Where $\rho_{\mathrm{s}}$ is sediment density and $d(\mathbf{x})$ is sediment thickness. Since it is hard to accurately constrain the detailed basement density distribution, we will assume that basement density in the research area is uniform.

There also exists a downward pulling force on the overlying lithosphere caused by the sinking of the subducted slab and transmitted by the asthenospheric wedge 203 (Flament et al., 2013; Gvirtzman et al., 2016; Husson, 2006). The topography changes 204 induced by this slab dynamic force are called 'dynamic topography' in this paper; the variation of this topography is predominantly long wavelength. The density contrast between the subducting slab and the mantle also causes a long-wavelength gravity perturbation, with this gravity anomaly referred to as 'dynamic gravity' or 'slab 
gravity anomaly' in this paper.

To evaluate the long-wavelength downward pulling force on the overlying 210 lithosphere by slab sinking, the sinking slab is separated into discrete elements. Based 211 on the Stokes stream function, the pulling force $(F)$ on a lithospheric surface point can 212 be calculated by (Husson, 2006; Morgan, 1965):

$$
F=\frac{3 \Delta \rho_{i j} v_{i j} g z_{i j}^{3}}{\pi r_{i j}^{5}}
$$

214 where $i, j$ is the slab element index, $\Delta \rho_{i j}$ is the density difference between this slab 215 unit and the background mantle, $v_{i j}$ is the volume of the unit, $g$ is the gravitational 216 acceleration, $z_{i j}$ is the depth of the unit and $r_{i j}$ is the distance between the slab unit 217 and the surface point. The overlying lithosphere will be bent downward, so when the 218 surface deflection is $h$ then the buoyancy force change of the overlying lithosphere 219 induced by this deflection is:

$$
\sigma=\left(\rho_{m}-\rho_{*}\right) g h
$$

221 where $\rho_{m}$ is mantle density and $\rho_{*}$ is seawater or air density. If it is a stress-free 222 surface then the buoyancy force change $(\sigma)$ should be equal to the slab pulling force 223 ( $F)$. Hence the total deflection $(H)$ of the lithosphere surface point by the 224 three-dimensional slab can be calculated by equating eqs (11) and (12) and summing 225 over all elements:

$$
H=\sum_{j} \sum_{i} \frac{3 \Delta \rho_{i j} v_{i j} z_{i j}^{3}}{\pi r_{i j}^{5}\left(\rho_{m}-\rho_{*}\right)}
$$

227 Except for the density perturbation of the slab unit $\left(\Delta \rho_{i j}\right)$, all the other parameters can 228 be assumed (Table 1) or calculated according to element coordinates. 
Here we compare three methods for slab-density modelling. First, Deschamps et

al. (2001) noted that both the lithosphere density $(\rho)$ and seismic shear-wave velocity

$(V s)$ are dependent on similar parameters, such as temperature, composition, pressure, etc.. This led Isaak et al. (1989) to derive a crude quantitative relationship between $\rho$ and $V s$ when only temperature affects $\rho$ and $V s$ :

$$
\zeta=\frac{\ln \rho-\ln \rho_{0}}{\ln V S-\ln V s_{0}}
$$

where the ratio $(\zeta)$ is 0.1 when depth is shallower than $400 \mathrm{~km}$, and 0.2 when depth is between $400 \mathrm{~km}$ and $700 \mathrm{~km}$, according to the study by Karato (1993). The parameters $\rho_{0}$ and $V s_{0}$ are reference density and shear-wave velocity, respectively; we call this method "Isaak1989". A second method for slab density modelling is based on conversion factor of $0.15 \mathrm{~cm}^{-3} \mathrm{~km}^{-1} \mathrm{~s}$; we call this method "KK2001". The third method we consider assigns a slab density anomaly of $25 \mathrm{~kg} \mathrm{~m}^{-3}$ relative to its surroundings, as Pérez-Gussinyé et al. (2008) assumed; we call this "PG2008".

After assuming slab thickness to be uniformly $100 \mathrm{~km}$ as $\underline{\text { Husson (2006) }}$ did, and extracting the shear-wave velocity of the subducted slab, the slab density perturbation can be derived from $V_{s}$ data and equation (14) by taking the Earth model of Dziewonski and Anderson (1981) as reference. The dynamic topography due to the slab density perturbation can then be calculated using equation (13). Additionally, the dynamic gravity due to the slab density perturbation can be calculated in the frequency domain (Oldenburg, 1974; Parker, 1973). The topography and gravity after removal of 
the slab effects are called here the 'residual' topography and gravity, respectively.

\section{CASE STUDY AT THE IBM SUBDUCTION ZONE}

\subsection{Geologic setting}

Subduction of the Pacific plate under the West Philippine Sea plate began by

-52-45 Ma (Arculus et al., 2015; Stern et al., 2004) and this subduction resulted in the

256 formation of the IBM Trench. The IBM subduction hinge roll back commenced with 257 the opening of two back-arc basins, the Shikoku and Parece Vela Basins, in the Late 258 Oligocene (Hall, 2002; Hilde et al., 1977; Honza and Fujioka, 2004). Part of the initial 259 volcanic arc remains on the western margin of these basins as a linear bathymetric 260 high named the Kyushu Palau Ridge (Figure 1). The seafloor spreading direction of related to rotation of the Philippine Sea plate (Hall, 1996; Sdrolias et al., 2004). These mid-ocean ridge spreading direction changes induced the formation of S-shaped fracture zones in these two basins (Sdrolias et al., 2004). Back-arc spreading in the Shikoku Basin and Parece Vela Basins ceased at 15 Ma.

A hiatus in back-arc spreading then occurred in this area until the Mariana Trough's initiation at $\sim 7 \mathrm{Ma}$, which is still spreading at the back of the Mariana Trench (Jolivet et al., 1989). Continuous subduction after cessation of the Shikoku and Parece Vela Basin's back-arc spreading resulted in widening of the Izu-Bonin-Mariana Arc. The previous Mariana Arc was split into two parts by the newly formed Marina 
Trough which is bounded by the West Mariana Arc and East Mariana Arc (Figure 1).

The region of the subducting Pacific plate in our research area which is older than

$274 \sim 130$ Ma (Müller et al., 2008) has cooled and subsided to great depths. Within this 275 region, the subduction systems form deep trenches and contain the lowest point (the 276 Challenger Deep) on the Earth's surface, at more than $10 \mathrm{~km}$ depth. The incoming 277 western Pacific plate is much older and denser than the over-riding Shikoku and 278 Parece Vela Basins (30 -15 Ma) (Sdrolias et al., 2004) and provides a large enough 279 negative buoyancy to sustain subduction (Hall et al., 2003; Niu, 2014). The subduction 280 process is, however, affected by the sea-bottom topography and density distribution of 281 the incoming Pacific plate (Zhang et al., 2016). For example, the docking of Bonin 282 (Ogasawara) Plateau (Figure 1b) which is about $2 \mathrm{~km}$ to $3 \mathrm{~km}$ higher than the 2018; Mason et al., 2010). 
bathymetry inverted from satellite altimetry data. The Bouguer anomaly grid by 295 Bureau Gravimétrique International (Balmino et al., 2012) is derived from the EGM2008 Geopotential model and the ETOPO1 Global Relief model, and this Bouguer grid is with 2 arc minutes resolution. The EGM2008 model includes surface gravity measurements, satellite altimetry and gravimetry measurements. Since our research area has thick water but thin sediment coverage (Amante and Eakins, 2009;

Divins, 2004), equivalent topography is computed only from the bathymetry using the seawater depth from ETOPO1. Global shear-wave velocity structure from surface to $700 \mathrm{~km}$ depth by Schaeffer and Lebedev (2013) is used for computing the dynamic of $0.5^{\circ}$ and a vertical resolution of $25 \mathrm{~km}$. 
3d) is much longer-wavelength in nature due to such wavelets tending to smear information out over larger spatial scales (Kirby and Swain, 2011). It is this property of higher-CW wavelets, despite their superior wavenumber-domain resolution, that make them less suited for studies where $T_{e}$ can change rapidly and by large amounts over short distances, as seems to be the case in this study area. To this end, we chose the smallest allowable value of $\left|\mathbf{k}_{0}\right|, 2.668$, in the following sections (which must be $>2.5$; Kirby and Swain, 2011).

Figure 4 shows the dynamic topography and gravity when the subducted slab's density structures are modelled with the PG2008, Isaak1989 and KK2001 methods, respectively. The dynamic topography and gravity results have a similar distribution but with reverse polarity because the positive density anomaly of the subducting slab induces a negative dynamic topography but positive gravity anomaly. Relatively large absolute dynamic topography and slab gravity anomaly values occur behind the trench, controlled by the density and position of the subducting slab (eq. (13)).

From the comparison between these three different groups of long-wavelength dynamic modelling results, we see that dynamic topography maps have a similar distribution trend but with different amplitudes. The smallest dynamic topography amplitude, with a value of $0.79 \mathrm{~km}$, is based on the Isaak1989 method; the largest dynamic topography amplitude, with a value of $2.32 \mathrm{~km}$, is based on the PG2008 method. The latter is almost three times the amplitude of the former. The dynamic gravity maps also have similar comparison characteristics. Therefore, different slab density modelling methods produce very different dynamic calculation results. 

anomaly and topography, giving residual quantities. The effective elastic thickness was then recomputed using the residual topography and gravity anomaly when $\mathrm{CW}=$

2.668 (Figure 5). A comparison between $T_{e}$ maps based on different slab density modelling methods (Figure 5) shows that these three $T_{e}$ maps have very similar trends and similar amplitudes even though the dynamic topography and gravity vary considerably when the slab density modelling method changes. These three $T_{e}$ maps also have very similar error distributions (Figure 6). Therefore, while dynamic topography and gravity values are relatively sensitive to slab density modelling, $T_{e}$ estimations derived from them are not. The $T_{e}$ values after application of the corrections are very much reduced, especially in the region surrounding the trench; this will be discussed in Section 3.5.

Figure 6 shows four $T_{e}$ error maps before and after application of dynamic corrections to the gravity and topography data. The errors are uniformly low over the majority of the study area, while the largest errors are distributed along the high- $T_{e}$ band surrounding the trench and on its boundary. The $T_{e}$ estimations without dynamic corrections have the largest errors of the four; the mean value of this $T_{e}$ error map (Figure 6a) is $2.7 \mathrm{~km}$ with a maximum error of $49.5 \mathrm{~km}$. The mean $T_{e}$ error after dynamic corrections when slab density is modelled based on the PG2008, Isaak 1989 and KK2001 methods, is reduced to $0.94 \mathrm{~km}, 0.93 \mathrm{~km}$ and $0.96 \mathrm{~km}$, respectively, and the maximum error of each $T_{e}$ map is $23.8 \mathrm{~km}, 21.0 \mathrm{~km}$ and $23.5 \mathrm{~km}$, respectively. Therefore, both the mean and maximum values of $T_{e}$ error have been considerably 
reduced by application of the dynamic corrections.

\subsection{Comparison with previous studies}

Two other studies have also mapped spatial variations of effective elastic

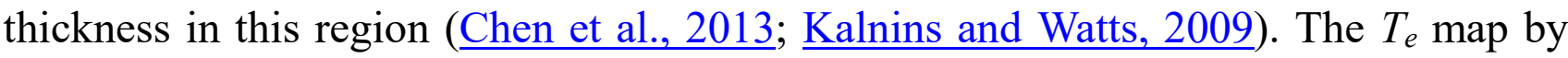
365 Chen et al. (2013) also used the Bouguer coherence method, though they used the multitaper method of spectral estimation, and used ETOPO2 for the topography/bathymetry data and free-air gravity anomalies from the EIGEN-6C model (http://icgem.gfz-potsdam.de/ICGEM/modelstab.html) to derive the Bouguer anomaly is; we call this study Chen2013. The $T_{e}$ map by Kalnins and Watts (2009) used the coincides with the study area of Chen2013, while the eastern section coincides with

Both KW2009 and Chen2013 both have a very similar high- $T_{e}$ band along the 
IBM Trench, and neither considered the effect of dynamic topography and gravity by the subducting slab. The spatial distribution of our high- $T_{e}$ band (Figure $7 \mathrm{~b}$ ) matches their geometries even though our methodology and input data are different from KW2009 and Chen2013. $T_{e}$ maps from all studies have a sharp $T_{e}$ transition on the boundaries of the high- $T_{e}$ band. The $T_{e}$ value along this band in Chen2013 is larger than $60 \mathrm{~km}$ which is similar to our first-step result (Figure 7a). The $T_{e}$ values along this band in KW2009 lie between $25-50 \mathrm{~km}$, a relatively small range compared to Chen2013, but still much larger than the surrounding $T_{e}$ values. Our peak value in the region overlapping with KW2009 is $37.2 \mathrm{~km}$. These observations demonstrate that, irrespective of which spectral analysis method is used (multitaper (Chen2013 and KW2009) or wavelet (our model)), high- $T_{e}$ values along the IBM Trench are the outcome. But as noted above, removal of dynamic topography and gravity from the bathymetry/topography and gravity reduces the amplitude of this high- $T_{e}$ band.

\subsection{Influence of dynamic correction on $T_{e}$ evaluation}

Both faulting and magmatic activity reduce lithospheric strength (Billen and Gurnis, 2005; Bry and White, 2007; Chen et al., 2013; McNutt and Menard, 1982; Zhang et al., 2014). Therefore, one would expect $T_{e}$ at the trench and its surrounding areas to have relatively small values. This is not seen in the $T_{e}$ maps computed before corrections of the gravity and topography data (Figure 3).

The mean value of the high- $T_{e}$ band bounded by black solid lines in Figure $7 \mathrm{a}$ is $76.7 \mathrm{~km}$; the removal of slab effects from the data reduces the mean value within this 
high- $T_{e}$ band by $56.9 \mathrm{~km}$ to $19.8 \mathrm{~km}$ (Figure $7 \mathrm{~b}$ ). Another difference between these two $T_{e}$ maps (Figure 7a and Figure $7 \mathrm{~b}$ ) is that the boundaries between the high- $T_{e}$ band and the adjacent regions are sharper in Figure $7 \mathrm{a}$ than in Figure $7 \mathrm{~b}$. Similar much wider than the high- $T_{e}$ band of Figure $7 \mathrm{~b}$. Reduction of the amplitude and width of the high- $T_{e}$ band has brought the $T_{e}$ value closer to the expectations of a curved, estimation results along oceanic trenches.

\subsection{Other possible influencing factors on $T_{e}$ evaluation}

The presence of a high- $T_{e}$ band after dynamic corrections were made (Figure 5)

illustrates that there are still some other factors affecting $T_{e}$ estimates. Besides slab sinking, the surrounding mantle flow and density variations could also modify topography and gravity as shown in Figure 2, and thus could affect $T_{e}$ estimates. But because the density and velocity of the upper mantle are affected not only by temperature but also by composition variations, it is difficult to image density distributions from seismic tomography. Therefore, density contrasts in the upper-most mantle have been ignored for dynamic studies (Conrad and Husson, 2009; $\underline{\text { Heine et al., }}$ 2008; Steinberger, 2007). The bottom depth of this section varies between different studies, for example, $220 \mathrm{~km}$ by Steinberger (2007) and Heine et al. (2008), and 300 km by Conrad and Husson (2009). Figure 8 shows that the mantle wedge has a clear low seismic velocity, but the mantle under the slab has a relatively uniform structure 
and small changes in velocity. These uncertainties provide the reason why we only consider slab dynamic effects.

Oceanic trenches and back-arc basins over a subducting slab are dynamically compensated by viscous mantle flow due to the force on the overriding plate induced by slab sinking and mantle wedge flow (Zhong and Gurnis, 1994). Stresses induced by slab sinking are transmitted along the slab to the surface, resulting in trench deepening, so the trench topography is compensated by the subducted slab (Davies, 1981). In this case, the compensation surface is not the Moho as supposed by the $2 \mathrm{D} T_{e}$ inversion method. Thus, $T_{e}$ estimates along the trench based on 2D inversion would be biased. Therefore, before estimating $T_{e}$ variations in subduction zones, other factors should be considered besides the slab dynamic effects on the overriding plate.

\section{CONCLUSIONS}

In this paper, we have attempted to study the effect of long-wavelength dynamic topography and gravity upon lithospheric effective elastic thickness estimation by taking the Izu-Bonin-Mariana Trench as a case study region. Dynamic topography and slab gravity anomaly induced by the subducted slab was estimated and then removed from the topography and gravity anomaly. The resulting residual topography and gravity anomaly were used to generate a $T_{e}$ map using the fan wavelet coherence method. $T_{e}$ maps generated before the removal of dynamic topography and slab gravity anomaly, and also the results of other studies (hen et al., 2013; $\underline{\text { Kalnins and }}$ Watts, 2009), reveal a high- $T_{e}$ band along and surrounding the IBM Trench, in 
448 disagreement with expectations of reduced $T_{e}$ due to heating, faulting and plate 449 curvature. However when the long-wavelength dynamic effects are applied, the 450 amplitude and width of this high $T_{e}$ band is strongly reduced, in keeping with 451 expectations. Our tests show that effective elastic thickness estimation results are 452 relatively insensitive to the particular method of slab-density estimation, despite the 453 model topography and gravity being more sensitive to model choice. The continued 454 presence of a high- $T_{e}$ band along the trench after application of dynamic corrections 455 shows that, before using 2D inversion methods to estimate Te variations in subduction 456 zones, there are other factors that should be considered besides the slab dynamic 457 effects on the overriding plate.

The authors thank the constructive comments and suggestions from two

\section{ACKNOWLEDGMENTS}

anonymous reviewers. This work is supported by National Natural Science Foundation of China (Grant No.41506055 and No.41476042), Open Fund of the Key Laboratory of Marine Geology and Environment CAS (MGE2017KG01), the Fundamental Research Funds for the Central Universities (No.17CX02003A) and Key Research Program of the Chinese Academy of Sciences (Grant No.Y10131).

\section{REFERENCES}

Amante, C., Eakins, B.W., 2009. ETOPO1 1 Arc-Minute Global Relief Model:

Procedures, Data Sources and Analysis, in: NGDC-24, N.T.M.N. (Ed.). National 
Arculus, R.J., et al., 2015. A record of spontaneous subduction initiation in the 472 Izu-Bonin-Mariana arc. Nature Geosci 8, 728-733.

Balmino, G., et al., 2012. Spherical harmonic modelling to ultra-high degree of 474 Bouguer and isostatic anomalies. Journal of Geodesy 86, 499-520. Billen, M.I., Gurnis, M., 2005. Constraints on subducting plate strength within the Kermadec trench. Journal of Geophysical Research: Solid Earth 110, B05407.

Bry, M., White, N., 2007. Reappraising elastic thickness variation at oceanic 478

Burov, E.B., Diament, M., 1995. The effective elastic thickness (Te ) of continental lithosphere: What does it really mean? Journal of Geophysical Research: Solid Earth 100, 3905-3927.

Chen, B., et al., 2013. Variations of the effective elastic thickness over China and surroundings and their relation to the lithosphere dynamics. Earth and Planetary 484 Science Letters 363, 61-72.

Chen, B., et al., 2015. Elastic thickness of the Himalayan-Tibetan orogen estimated from the fan wavelet coherence method, and its implications for lithospheric structure. Earth and Planetary Science Letters 409, 1-14.

Conrad, C.P., Husson, L., 2009. Influence of dynamic topography on sea level 
and its rate of change. Lithosphere 1, 110-120.

Contreras-Reyes, E., Osses, A., 2010. Lithospheric flexure modelling seaward of the Chile trench: implications for oceanic plate weakening in the Trench Outer Rise region. Geophysical Journal International 182, 97-112.

Davies, G.F., 1981. Regional compensation of subducted lithosphere: effects on geoid, gravity and topography from a preliminary model. Earth and Planetary Science Letters 54, 431-441.

Deschamps, F., et al., 2001. The relative density-to-shear velocity scaling in the uppermost mantle. Physics of the Earth and Planetary Interiors 124, 193-212.

Divins, D.L., 2004. Total Sediment Thickness of the World's Oceans \& 499

Dziewonski, A.M., Anderson, D.L., 1981. Preliminary reference Earth model.

Ebinger, C.J., et al., 1989. Effective elastic plate thickness beneath the East

Flament, N., et al., 2013. A review of observations and models of dynamic topography. Lithosphere 5, 189-210.

Forsyth, D., Uyeda, S., 1975. On the Relative Importance of the Driving Forces 
of Plate Motion. Geophysical Journal of the Royal Astronomical Society 43, 163-200.

Forsyth, D.W., 1985. Subsurface loading and estimates of the flexural rigidity of 510 continental lithosphere. Journal of Geophysical Research: Solid Earth 90, 12623-12632.

Gvirtzman, Z., et al., 2016. Isostasy, flexure, and dynamic topography. 513 Tectonophysics 683, 255-271.

Hall, C.E., et al., 2003. Catastrophic initiation of subduction following forced convergence across fracture zones. Earth and Planetary Science Letters 212, 15-30.

Hall, R., 1996. Reconstructing Cenozoic SE Asia. Geological Society, London, Special Publications 106, 153-184.

Hall, R., 2002. Cenozoic geological and plate tectonic evolution of SE Asia and the SW Pacific: computer-based reconstructions, model and animations. Journal of 520 Asian Earth Sciences 20,353-431.

Heine, C., et al., 2008. Subsidence in intracontinental basins due to dynamic 522 topography. Physics of the Earth and Planetary Interiors 171, 252-264.

Hilde, T.W.C., et al., 1977. Present State of Plate Tectonics Evolution of the 524 western pacific and its margin. Tectonophysics 38, 145-165.

Honza, E., Fujioka, K., 2004. Formation of arcs and backarc basins inferred 526 from the tectonic evolution of Southeast Asia since the Late Cretaceous. 
Hunter, J., Watts, A.B., 2016. Gravity anomalies, flexure and mantle rheology seaward of circum-Pacific trenches. Geophysical Journal International 207, 288-316.

Husson, L., 2006. Dynamic topography above retreating subduction zones.

531 Geology 34, 741-744.

IOC, I., BODC,, 2003. Centenary edition of the GEBCO Digital Atlas, published on behalf of the Intergovernmental Oceanographic Commission and the 534 International Hydrographic Organization as part of the General Bathymetric Chart of 535 the Oceans, in: Centre, B.O.D. (Ed.), Liverpool, U.K.

Isaak, D.G., et al., 1989. Elasticity of single-crystal forsterite measured to 1700

Jolivet, L., et al., 1989. Subduction Zones: The Kaiko Project Tectonic setting of

Kalnins, L.M., Watts, A.B., 2009. Spatial variations in effective elastic thickness 541 in the Western Pacific Ocean and their implications for Mesozoic volcanism. Earth and 542 Planetary Science Letters 286, 89-100.

Karato, S.-i., 1993. Importance of anelasticity in the interpretation of seismic 544 tomography. Geophysical Research Letters 20, 1623-1626.

Karato, S.-i., Karki, B.B., 2001. Origin of lateral variation of seismic wave 
546 velocities and density in the deep mantle. Journal of Geophysical Research 106, $547 \quad 21771-21783$.

Kirby, J.F., 2005. Which wavelet best reproduces the Fourier power spectrum? 549 Computers \& Geosciences 31, 846-864.

Kirby, J.F., 2014. Estimation of the effective elastic thickness of the lithosphere 551 using inverse spectral methods: The state of the art. Tectonophysics $631,87-116$.

Kirby, J.F., Swain, C.J., 2004. Global and local isostatic coherence from the 553 wavelet transform. Geophysical research letters 31, L24608.

Kirby, J.F., Swain, C.J., 2008. An accuracy assessment of the fan wavelet 555 coherence method for elastic thickness estimation. Geochemistry, Geophysics, 556 Geosystems 9, Q03022.

Kirby, J.F., Swain, C.J., 2011. Improving the spatial resolution of effective 558 elastic thickness estimation with the fanwavelet transform. Computers \&Geosciences $559 \quad 37,1345-1354$.

Kirby, J.F., Swain, C.J., 2013. Power spectral estimates using two-dimensional 561 Morlet-fan wavelets with emphasis on the long wavelengths: jackknife errors, 562 bandwidth resolution and orthogonality properties. Geophysical Journal International $563194,78-99$.

Kong, X., et al., 2018. Causes of earthquake spatial distribution beneath the 
Müller, R.D., et al., 2008. Age, spreading rates, and spreading asymmetry of the 567 world's ocean crust. Geochemistry, Geophysics, Geosystems 9, Q04006.

Macario, A., et al., 1995. On the robustness of elastic thickness estimates obtained using the coherence method. Journal of Geophysical Research: Solid Earth 570 $100,15163-15172$.

Mason, W.G., et al., 2010. Three-dimensional numerical models of the influence 572 of a buoyant oceanic plateau on subduction zones. Tectonophysics 483, 71-79.

McKenzie, D., Fairhead, D., 1997. Estimates of the effective elastic thickness of 574 the continental lithosphere from Bouguer and free air gravity anomalies. Journal of 575 Geophysical Research: Solid Earth 102, 27523-27552.

McNutt, M.K., Menard, H.W., 1982. Constraints on yield strength in the 577 oceanic lithosphere derived from observations of flexure. Geophys J Int 71, 363-394.

Morgan, W.J., 1965. Gravity anomalies and convection currents: 1. A sphere and 579 cylinder sinking beneath the surface of a viscous fluid. Journal of Geophysical 580 Research 70, 6175-6187.

Niu, Y., 2014. Geological understanding of plate tectonics: Basic concepts, 582 illustrations, examples and new perspectives. Global Tectonics and Metallogeny 10, 583 23-46. 
Oldenburg, D., 1974. The inversion and interpretation of gravity anomalies.

585 Geophysics 39, 526-536.

Oruç, B., Sönmez, T., 2017. The rheological structure of the lithosphere in the 587 Eastern Marmara region, Turkey. Journal of Asian Earth Sciences 139, 183-191.

Pérez-Gussinyé, M., et al., 2008. Effective elastic thickness variations along the 589 Andean margin and their relationship to subduction geometry. Geochemistry, 590 Geophysics, Geosystems 9, Q02003.

Pérez-Gussinyé, M., et al., 2004. On the recovery of effective elastic thickness using spectral methods: Examples from synthetic data and from the Fennoscandian

Parker, R.L., 1973. The Rapid Calculation of Potential Anomalies. Geophysical 595 Journal International 31, 447-455.

Press, W.H., et al., 1992. Numerical Recipes in Fortran 77, Second ed. 597 Cambridge University Press, Cambridge.

Ratheesh Kumar, R.T., et al., 2013. Elastic thickness structure of the Andaman 599 subduction zone: Implications for convergence of the Ninetyeast Ridge. Journal of 600 Asian Earth Sciences 78, 291-300.

Schaeffer, A.J., Lebedev, S., 2013. Global shear speed structure of the upper 602 mantle and transition zone. Geophysical Journal International 194, 417-449. 
Sdrolias, M., et al., 2004. An expression of Philippine Sea plate rotation: the 604 Parece Vela and Shikoku Basins. Tectonophysics 394, 69-86.

Shi, X., et al., 2017. Spatial variations in the effective elastic thickness of the 606

Simons, F.J., Olhede, S.C., 2013. Maximum-likelihood estimation of 608 lithospheric flexural rigidity, initial-loading fraction and load correlation, under 609 isotropy. Geophysical Journal International 193, 1300-1342.

Simons, F.J., et al., 2000. Isostatic response of the Australian lithosphere:

611 Estimation of effective elastic thickness and anisotropy using multitaper spectral 612 analysis. Journal of Geophysical Research: Solid Earth 105, 19163-19184.

Smith, W.H.F., Sandwell, D.T., 1994. Bathymetric prediction from dense 614 satellite altimetry and sparse shipboard bathymetry. Journal of Geophysical Research: 615 Solid Earth 99, 21803-21824.

Steinberger, B., 2007. Effects of latent heat release at phase boundaries on flow 617 in the Earth's mantle, phase boundary topography and dynamic topography at the 618 Earth's surface. Physics of the Earth and Planetary Interiors 164, 2-20.

Stern, R.J., et al., 2004. An Overview of the Izu-Bonin-Mariana Subduction 620 Factory, Inside the Subduction Factory. American Geophysical Union, pp. 175-222. 
622 from wavelet transforms of gravity and topography using Forsyth's method. 623 Geophysical Research Letters 33, L02314.

624 Thomson, D.J., Chave, A.D., 1991. Jackknifed error estimates for spectra, 625 coherences, and transfer functions. Prentice Hall, Englewood Cliffs, N.J.

Walcott, R.I., 1970. Flexural rigidity, thickness, and viscosity of the lithosphere.

627 Journal of Geophysical Research 75, 3941-3954.

Watts, A.B., et al., 1980. Observations of flexure and the state of stress in the 629 oceanic lithosphere. Journal of Geophysical Research: Solid Earth 85, 6369-6376.

630

Zhang, B., et al., 2016. Docking and subduction of the West Pacific seamounts 631 along the Mariana Trench and their effects. Geological Journal 51, 579-592.

Zhang, F., et al., 2014. Variations in oceanic plate bending along the Mariana 633 trench. Earth and Planetary Science Letters 401, 206-214.

Zhong, S., Gurnis, M., 1994. Controls on trench topography from dynamic 635 636 models of subducted slabs. Journal of Geophysical Research: Solid Earth 99, 15683-15695. 
Table 1 Physical constants for $T_{e}$ estimation after Ratheesh Kumar et al. (2013)

\begin{tabular}{llll}
\hline Constant & symbol & value & Unit \\
\hline Young modulus & $E$ & $10^{11}$ & $\mathrm{~Pa}$ \\
Newtonian gravitational constant & $G$ & $6.67 \times 10^{-11}$ & $\mathrm{~m}^{3} \mathrm{~kg}^{-1} \mathrm{~s}^{-2}$ \\
Poisson ratio & $v$ & 0.25 & \\
gravitational acceleration & $g$ & 9.81 & $\mathrm{~m} / \mathrm{s}^{2}$ \\
seawater density & $\rho_{w}$ & 1030 & $\mathrm{~kg} / \mathrm{m}^{3}$ \\
basement density & $\rho_{b}$ & 2800 & $\mathrm{~kg} / \mathrm{m}^{3}$ \\
mantle density & & & \\
\hline
\end{tabular}

640

641

642 


\section{FIGURES}
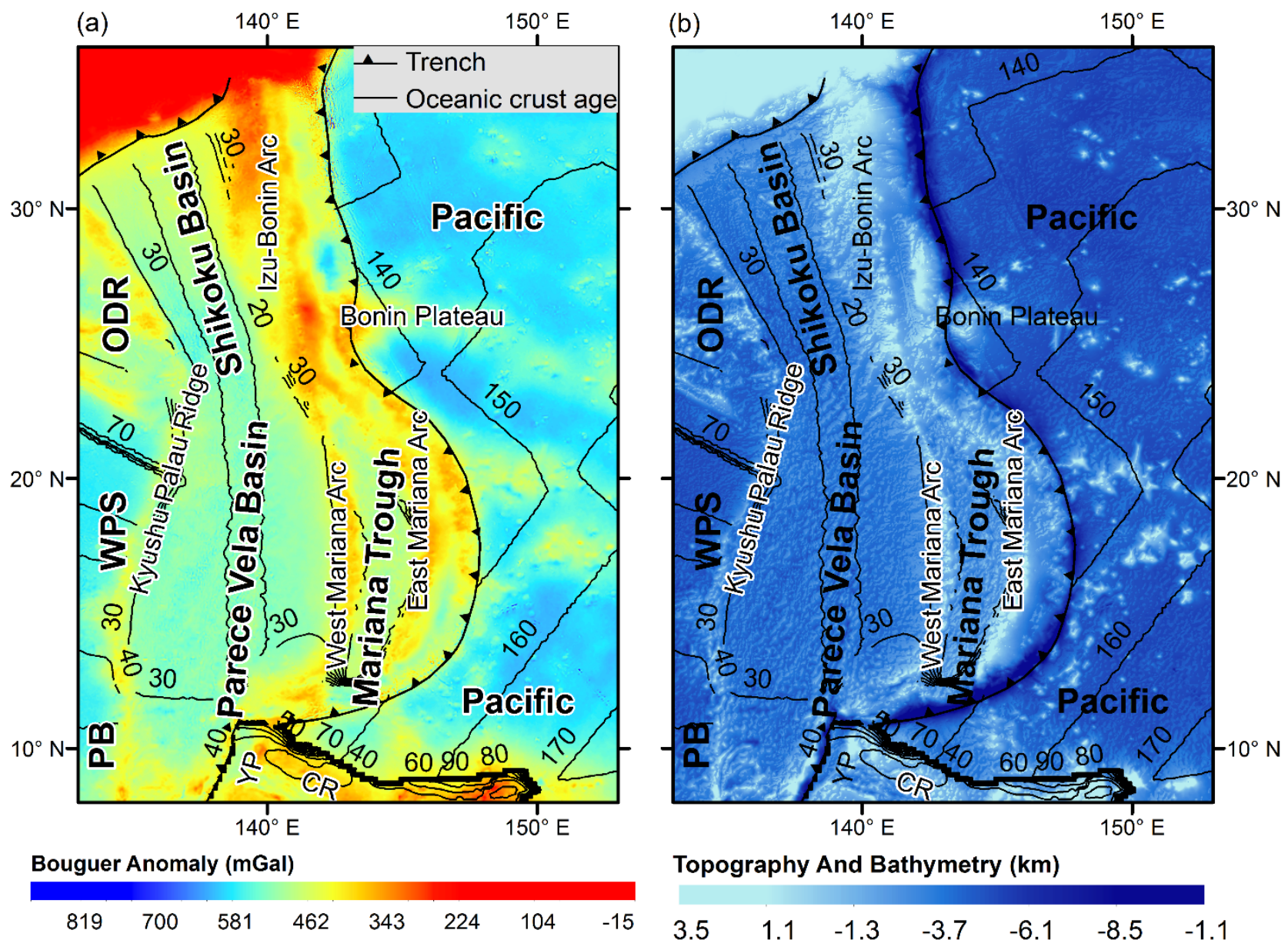

Topography And Bathymetry (km)

$\begin{array}{lllllll}3.5 & 1.1 & -1.3 & -3.7 & -6.1 & -8.5 & -1.1\end{array}$

645 Figure 1. (a) The Bouguer gravity anomaly from the Bureau Gravimétrique

646 International (Balmino et al., 2012), and (b) the topography and bathymetry from

647 ETOPO1 (Amante and Eakins, 2009), of the IBM subduction system and surroundings.

648 The oceanic crustal age contour (labelled in m.y.) is based on the age grid provided by

649 Müller et al. (2008). Abbreviations: WPS, West Philippine Sea; ODR, Oki-Daito

650 Ridge; PB, Palau Basin; YT, Yap Trench; CR, Caroline Ridge. 


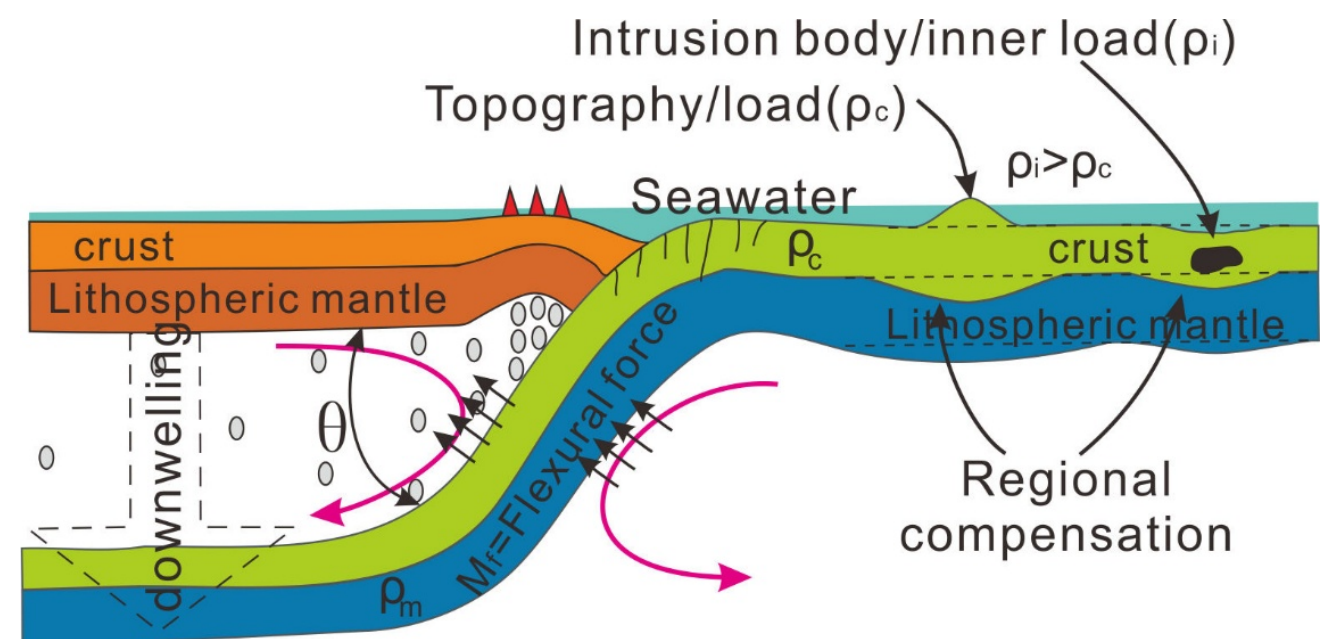

653 Figure 2. Cartoon showing compensation mode and subduction dynamics. The dashed 654 lines represent the initial topography, Moho and lithospheric bottom. Subsequent 655 magmatic intrusion and mountain formation results in lithospheric bending and 656 compensation surface adjustment. Viscous asthenosphere transmits the dynamic forces 657 due to slab sinking to the overlying plate and induces topography changes. Water 658 released from dehydration of the subducted slab results in lithospheric partial melting 659 and reduction of lithospheric strength (Chen et al., 2013). Pink arrows represent 660 mantle flow at different locations (Pérez-Gussinyé et al., 2008). $\theta$ is the subduction 661 angle. 


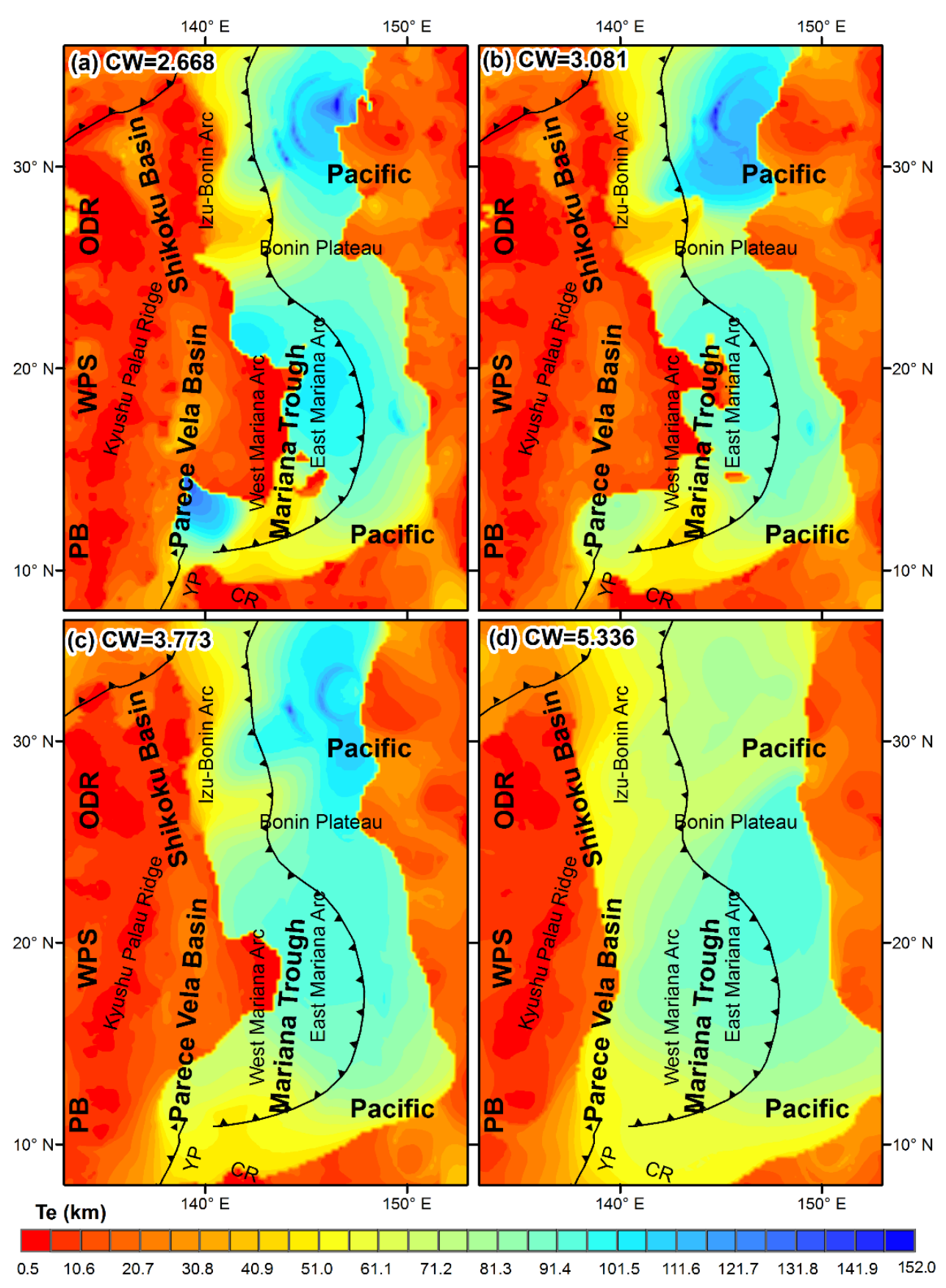

Figure 3. $T_{e}$ estimation results (without slab corrections) based on four different

665 central wavenumber $(\mathrm{CW})$ values. Abbreviations can be found in the caption to Figure 6661. 

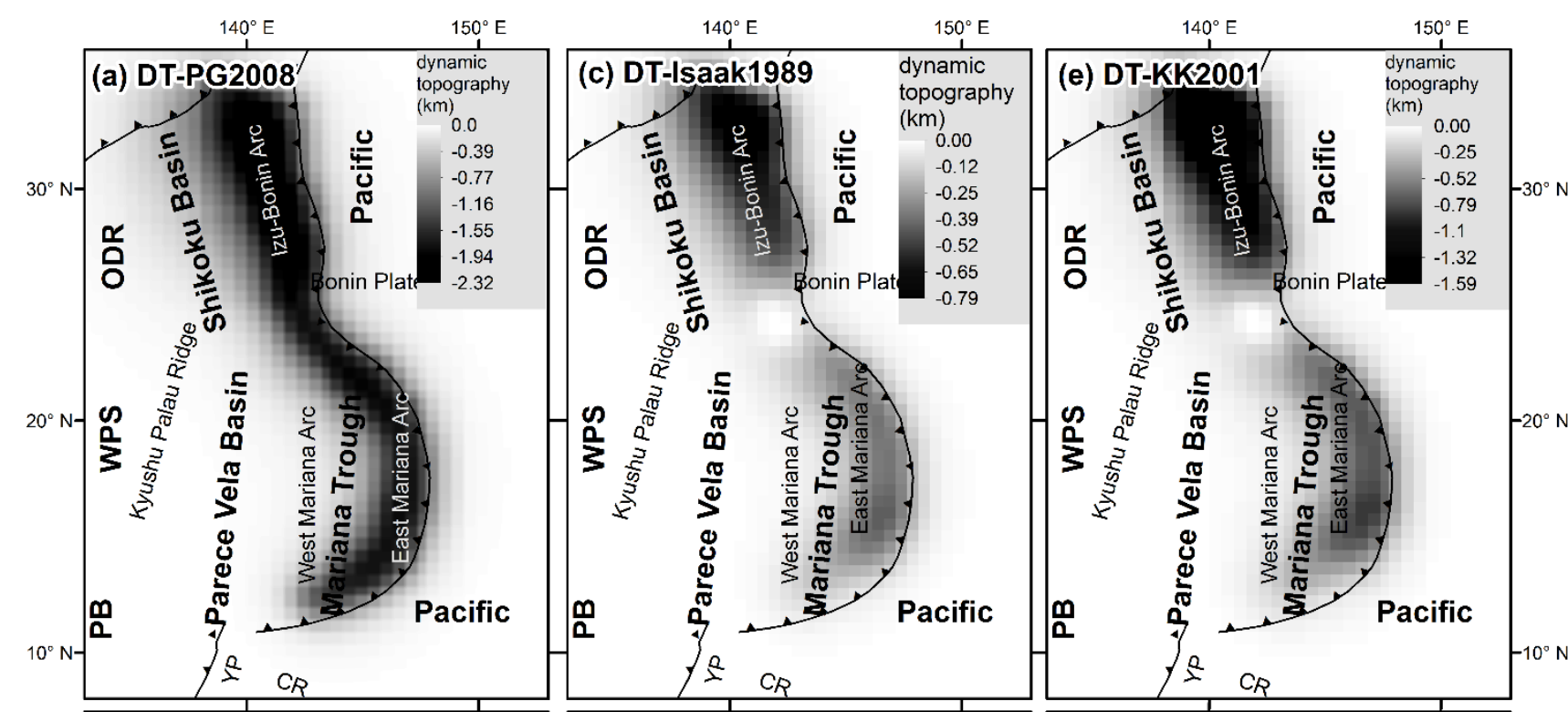

668
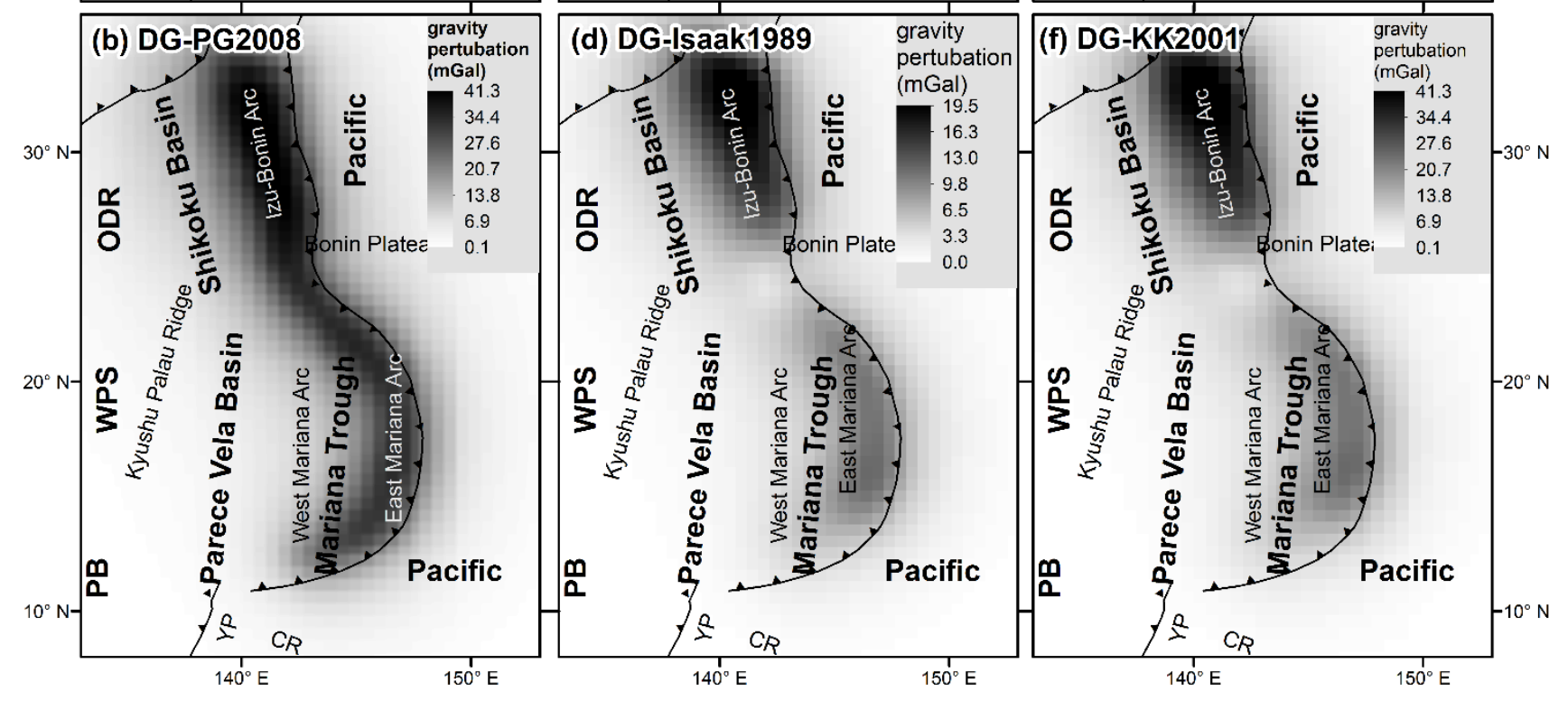

669 Figure 4. Dynamic topography (DT) on the top panels and dynamic gravity (DG) on

670 the bottom panels induced by the sinking of the subducted Pacific plate when the slab

671 density is based on the PG2008, Isaak1989 and KK2001 methods, respectively. See

672 Figure 1 for abbreviations. 


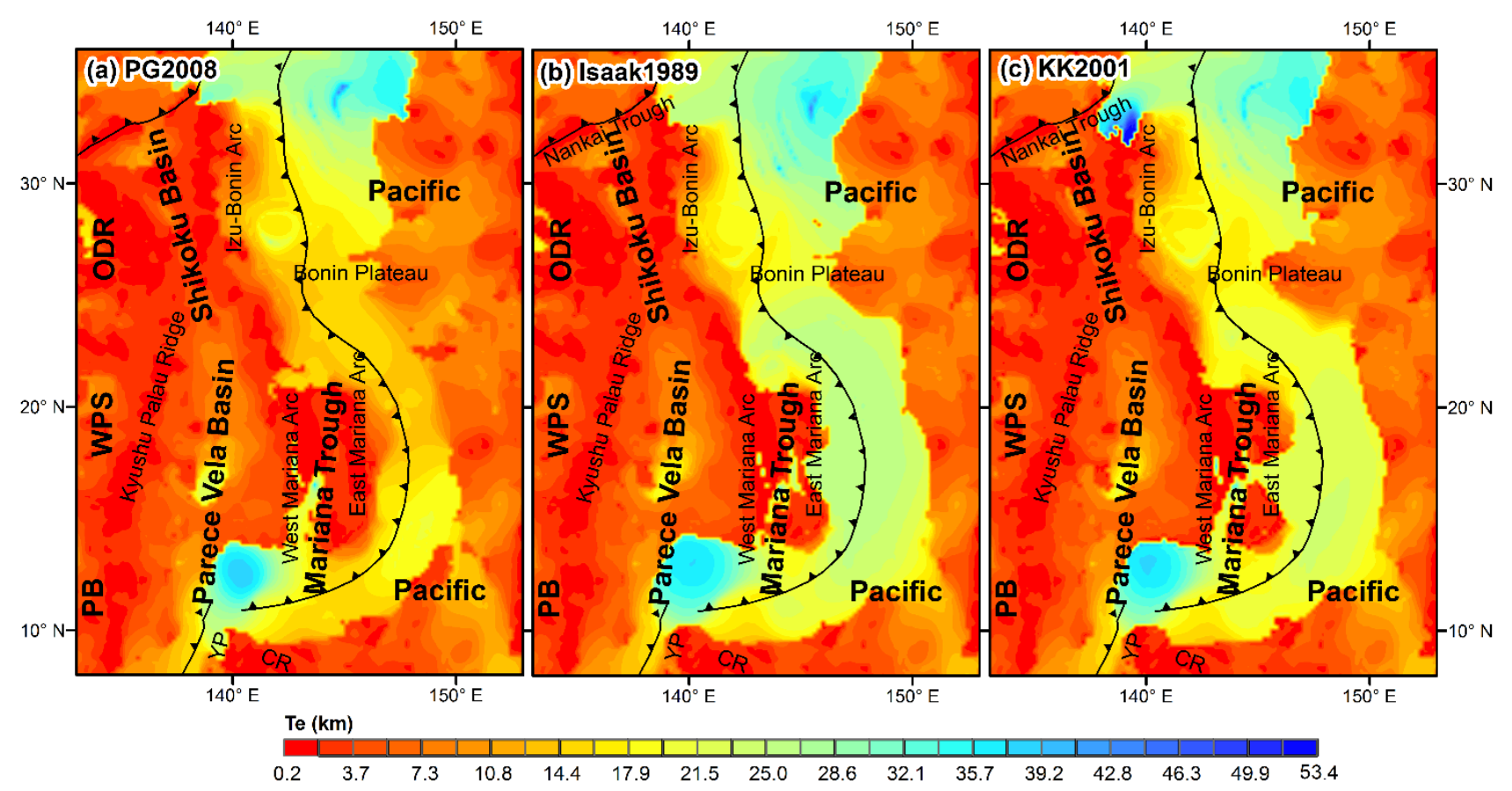

674

675 Figure 5. $T_{e}$ maps using residual gravity and topography, when the subducted slab

676 density is modelled using the PG2008, Isaak1989 and KK2001 methods, respectively

677 (central wavenumber is 2.668 in all). Abbreviations are the same as Figure 1. 


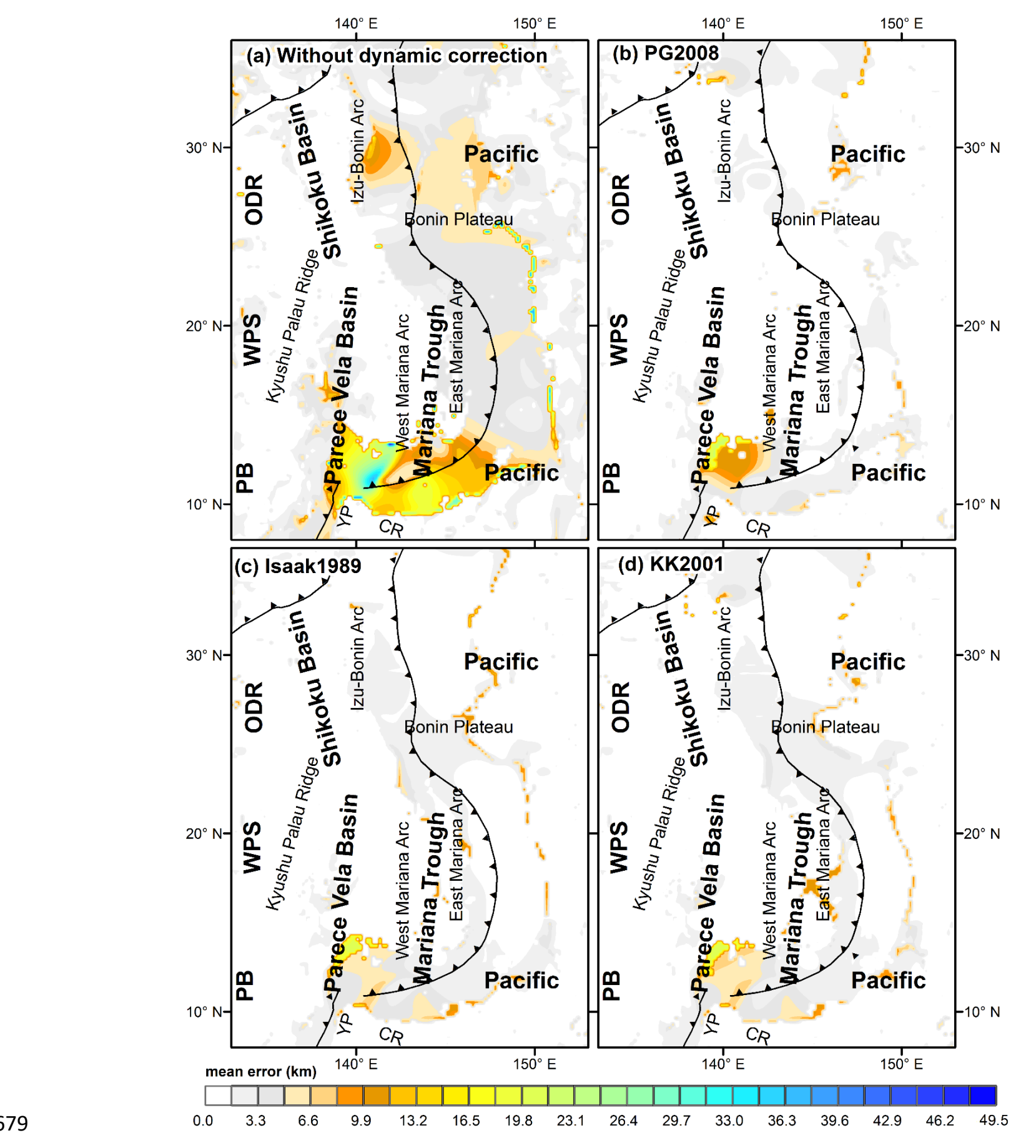

680 Figure 6. $T_{e}$ error maps (a) without dynamic corrections to the gravity and topography 681 data, and when dynamic corrections are based on the (b) PG2008, (c) Isaak 1989, and 682 (d) KK2001 methods, respectively. The central wavenumber for all maps is 2.668. 

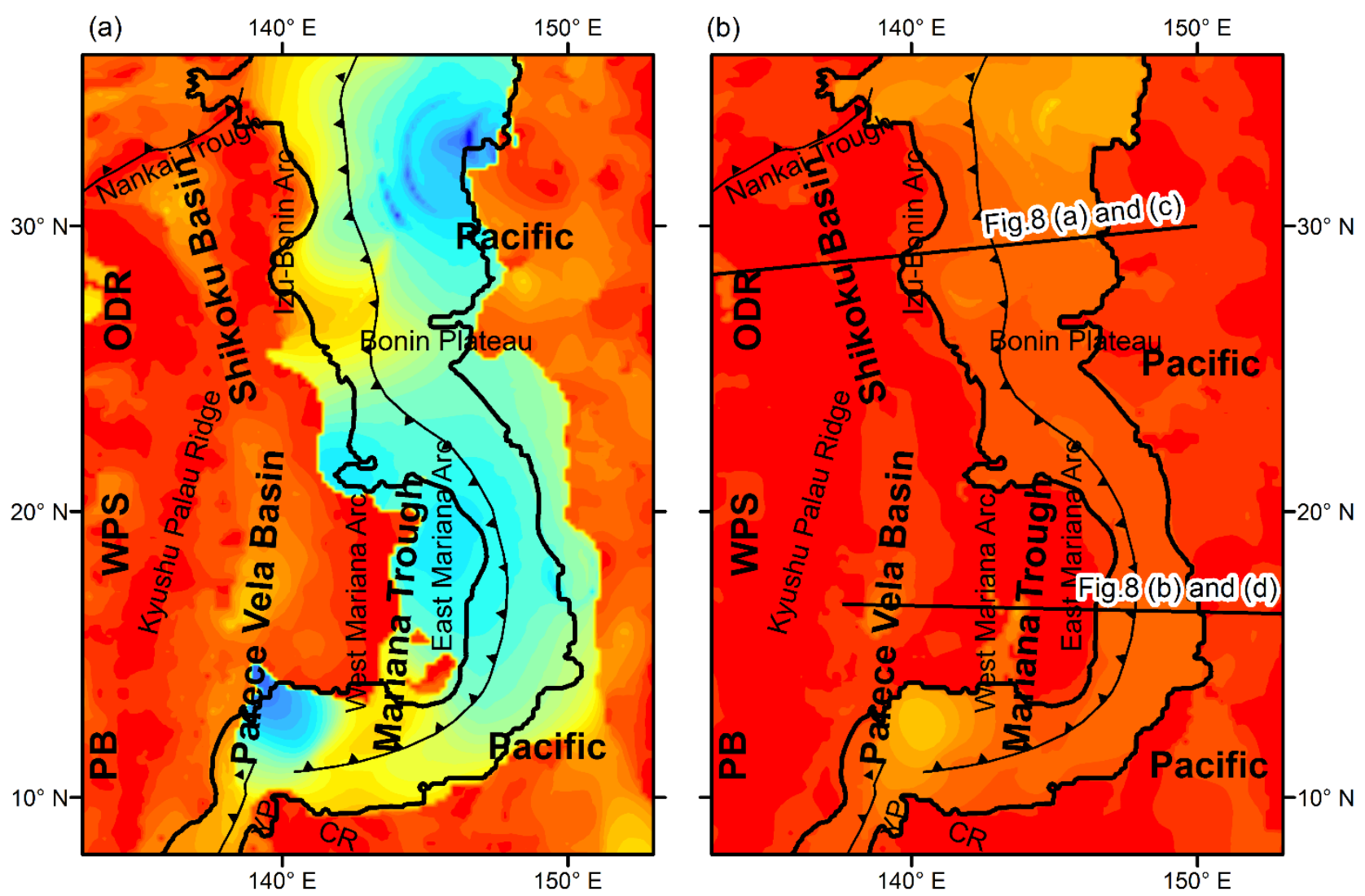

$\mathrm{Te}(\mathrm{km})$

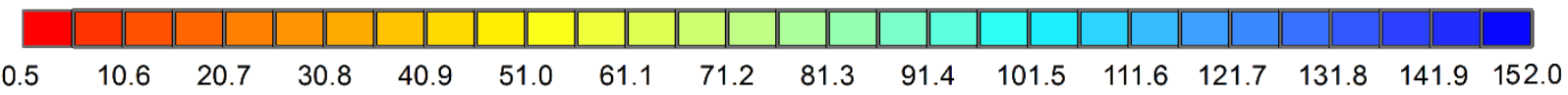

686 Figure 7. $T_{e}$ maps (a) before and (b) after considering the influence of pull-force by the 687 subducted slab of the Pacific plate on topography and gravity $(\mathrm{CW}=2.668)$. The solid 688 black lines in (a) and (b) are the outer boundaries of the high- $T_{e}$ band from Figure $5 \mathrm{~b}$. 689 (a) is a reproduction of Figure 3a, while (b) is a reproduction of Figure 5b. All 690 abbreviations are the same as Figure 1. 

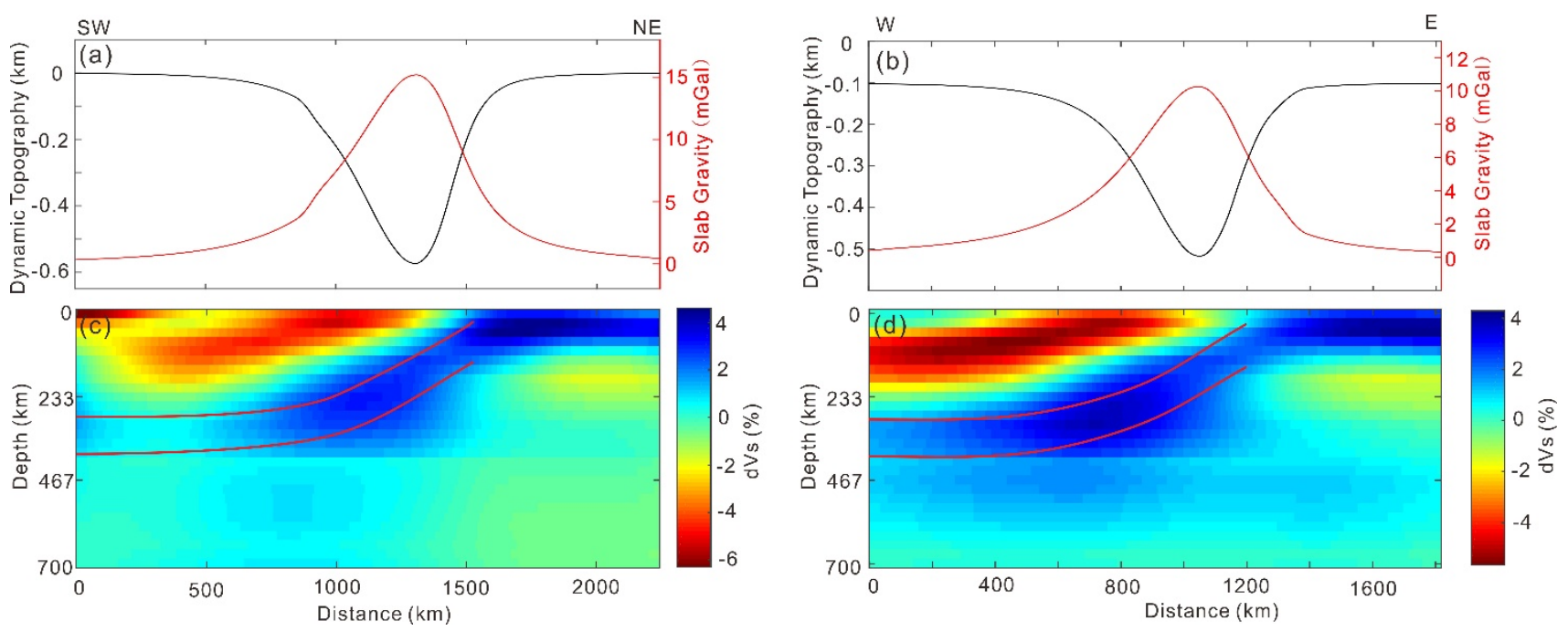

693 Figure 8. Two profiles show seismic velocity structure (on bottom panel), dynamic 694 topography and slab gravity (black and right curve respectively on top panel). Slab 695 density modelling is based on the Isaak1989 method for dynamic effect calculations. 696 The red curves on the bottom show the slab geometries with $100 \mathrm{~km}$ thickens. The 697 profile locations are shown in Figure 7. 